\title{
Inhibition of hepatitis B virus (HBV) gene expression and replication by $H B x$ gene silencing in a hydrodynamic injection mouse model with a new clone of HBV genotype B
}

Lei Li ${ }^{1,2}$, Hong Shen ${ }^{1}$, Anyi Li $i^{4}$, Zhenhua Zhang ${ }^{1}$, Baoju Wang ${ }^{1}$, Junzhong Wang ${ }^{1}$, Xin Zheng ${ }^{1}$, Jun Wu', Dongliang Yang ${ }^{1}$, Mengji Lu ${ }^{5}$ and Jingjiao Song ${ }^{3^{*}}$

\begin{abstract}
Background: It has been suggested that different hepatitis B virus (HBV) genotypes may have distinct virological characteristics that correlate with clinical outcomes during antiviral therapy and the natural course of infection. Hydrodynamic injection (HI) of HBV in the mouse model is a useful tool for study of HBV replication in vivo. However, only HBV genotype A has been used for studies with $\mathrm{HI}$.

Methods: We constructed 3 replication-competent clones containing 1.1, 1.2 and 1.3 fold overlength of a HBV genotype B genome and tested them both in vitro and in vivo. Moreover, A HBV genotype B clone based on the PAAV-MCS vector was constructed with the 1.3 fold HBV genome, resulting in the plasmid PAAV-HBV1.3 and tested by $\mathrm{HI}$ in C57BL/6 mice. Application of siRNA against HBx gene was tested in HBV genotype B HI mouse model.

Results: The 1.3 fold HBV clone showed higher replication and gene expression than the 1.1 and 1.2 fold HBV clones. Compared with pAAV-HBV1.2 (genotype A), the mice HI with PAAV-HBV1.3B showed higher HBsAg and HBeAg expression as well as HBV DNA replication level but a higher clearance rate. Application of two plasmids pSB-HBxi285 and pSR-HBxi285 expressing a small/short interfering RNA (siRNA) to the HBx gene in HBV genotype B HI mouse model, leading to an inhibition of HBV gene expression and replication. However, HBV gene expression may resume in some mice despite an initial delay, suggesting that transient suppression of HBV replication by siRNA may be insufficient to prevent viral spread, particularly if the gene silencing is not highly effective.

Conclusions: Taken together, the HI mouse model with a HBV genotype B genome was successfully established and showed different characteristics in vivo compared with the genotype A genome. The effectiveness of gene silencing against $H B x$ gene determines whether HBV replication may be sustainably inhibited by siRNA in vivo.
\end{abstract}

Keywords: Hydrodynamic injection, HBV mouse model, HBV genotype B, HBx gene silencing, Antiviral research

\footnotetext{
* Correspondence: jjsong@tjh.tjmu.edu.cn

${ }^{3}$ Division of Clinical Immunology, Tongji Hospital, Tongji Medical College,

Huazhong University of Science and Technology, Wuhan, P.R. China

Full list of author information is available at the end of the article
} 


\section{Introduction}

Hepatitis B virus (HBV) causes acute and chronic infection in the human liver and subsequently hepatic cirrhosis and hepatocellular carcinoma (HCC) that severely affects human health [1-3]. Although a highly effective vaccine is now available for the prevention of new HBV infections, about 400 million people worldwide have already been chronically infected and suffer from chronic liver injury [4].

An immunologically well-characterized small animal model for HBV infection remains unavailable due to the strict host specificity of HBV infection, which greatly hampers HBV-related research. The laboratory mouse is genetically and immunologically defined, and a large collection of genetically modified animals exists. However, mice can not be infected with HBV. Several lines of transgenic mice with replication competent HBV genomes have been established and represented to be powerful tools for HBV research [5]. However, HBV replication in the transgenic mice is generated from the integrated HBV sequence harbored in all hepatocytes, which is different from what occurs during a natural infection [5-8]. The presence of $\mathrm{HBV}$ genomes in these mouse lines inevitably induces immune tolerance to the HBV antigens. In addition, the capability of production of transgenic mouse model is not readily available in ordinary laboratory conditions. Transplant mouse models were established and used for different studies [9-11]. However, the models are based on immunodeficient mouse strains and difficult to handle in the laboratory.

Hydrodynamic injection (HI) of replication-competent HBV DNA into the tail veins of mice can establish HBV replication in the mouse liver [12,13]. In $40 \%$ of injected C56BL/6 mice, the persistence of HBV surface antigenemia (HBsAg) was greater than 6 months. HBV persistence is determined by the mouse genetic background and plasmid backbone [12]. The HBV HI mouse model is a highly interesting model for testing vaccination strategies and mechanisms of viral persistence [14-18]. This model may be used to the study replication competence of HBV constructs [15]. Previously, the established HBV HI mouse models were based on HBV genotype A replicationcompetent clones [12,13]. As HBV genotypes B and C are highly prevalent in Asia and may have distinct virological characteristics that correlate with clinical outcomes in the natural course of infection and antiviral therapy, it is warranted to establish HBV HI mouse models with characterized HBV strains.

Patients with chronic HBV infection are currently treated with interferon alpha (IFN- $\alpha$ ) or nucleotide analogs such as entecavir and tenofovir. However, the current therapies have only a limited success rate and frequent viral recurrence after cessation of therapy, therefore, new antiviral strategies are required $[19,20]$.
RNA interference has been developed as potential therapeutic approaches [21-24]. In previous studies, siRNAs targeting different regions of the HBV genome were used. The $H B x$ gene encodes a small non-structural protein that has diverse functions and is required for HBV efficient replication [25,26]. The $H B x$ mRNA contains the common sequence of the four transcripts of HBV $[25,27,28]$, which makes it a potentially useful target for antiviral therapy.

In this study, we addressed the question whether a replication competent HBV genotype B clone could replicate transiently and persistently in HI mouse model. Plasmids pSB-HBxi285 (non-viral vector) and pSR-HBxi285 (retroviral vector) that express siRNA targeting the $H B x$ gene were constructed. Using these constructs, we asked how the gene silencing by $H B x$ siRNA of genotype B influences the course of $\mathrm{HBV}$ replication and persistence in the $\mathrm{HI}$ mouse model.

\section{Results}

\section{Identification of different folds of HBV DNA expression} plasmids

The 1.1, 1.2 and 1.3 fold over-length HBV genome DNA including nt 1658-3215-1986, nt 1360-3215-1986 and nt 1040-3215-1986 were cloned into the pBluesript II KS (+) vector separately. The construction procedure is shown in Additional file 1: Figure S1A and schematic representation of the 1.1, 1.2 and 1.3 fold HBV genome are shown in Additional file 1: Figure S1B. The plasmids were analyzed by restriction enzyme digestion with PstI and SacI. Pst I and $\mathrm{SacI}$ restriction digestion of pBS-HBV1.1 $1_{\mathrm{B}}$, pBSHBV1. $2_{\mathrm{B}}$ and $\mathrm{pBS}-\mathrm{HBV} 1.3_{\mathrm{B}}$ resulted in the appearance of additional bands of $3.5,3.8$ and $4.2 \mathrm{~kb}$ in addition to the pBluescript II KS (+) vector, respectively (Additional file 2 : Figure S2). Consistently, Pst I restriction digestion of pBSHBV1.1 $1_{\mathrm{B}}$, PBS-HBV1.2 $2_{\mathrm{B}}$ and $\mathrm{pBS}-\mathrm{HBV} 1.3_{\mathrm{B}}$ confirmed that these vectors have the sizes of $6.5,6.8$ and $7.2 \mathrm{~kb}$, respectively (Additional file 2: Figure S2). The HBV 1.3 fold over length genome DNA was amplified and sub-cloned into the NotI site of the pAAV-MCS vector (Agilent technologies, La Jolla, USA). The construction procedure of pAAV-HBV1.3 ${ }_{B}$ is shown in Additional file 1: Figure S1C. The plasmid pAAV-HBV1.3 $3_{\mathrm{B}}$ was identified by Not $\mathrm{I}$ restriction digestion and an additional band of $4.16 \mathrm{~kb}$ (data not shown).

\section{pBS-HBV1.3 ${ }_{B}$ shows high replication competence both in vitro and in vivo}

To investigate the functionality of pBS-HBV1.1 $1_{B}$, pBSHBV1.2 $2_{B}$ and pBS-HBV1. $3_{B}$ in hepatoma cells, the plasmids were transfected into Huh-7 cells. At 48 h posttransfection, the culture supernatants of the transfected cells were harvested and subjected to $\mathrm{HBsAg}$ and $\mathrm{HBeAg}$ detection. As shown in Figure 1A, the HBsAg and $\mathrm{HBeAg}$ 

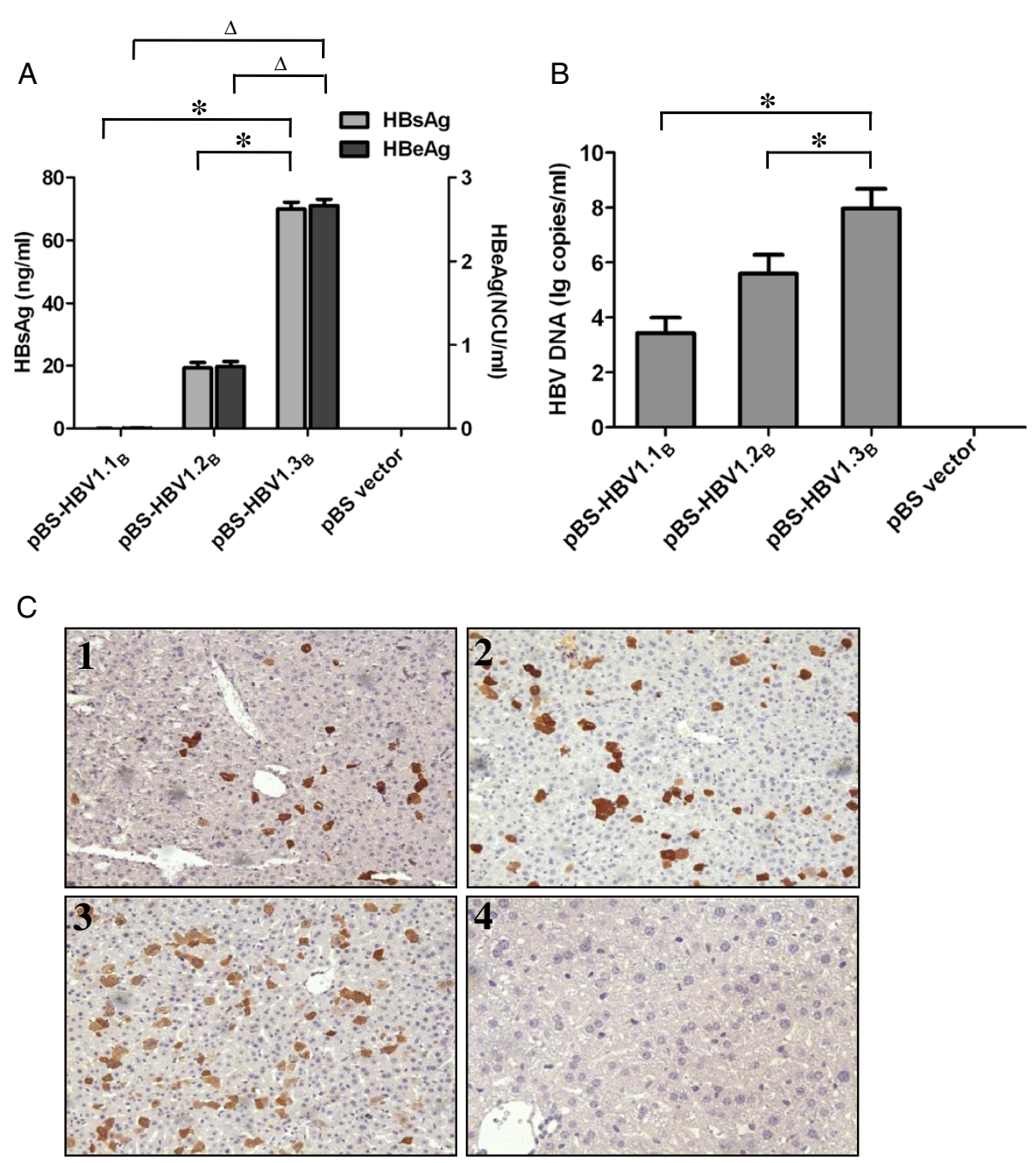

Figure 1 Comparison of the in vitro and in vivo replication competence of pBS-HBV1.1 $1_{B}, \mathrm{pBS}-\mathrm{HBV} 1.2_{\mathrm{B}}$ and pBS-HBV1.3B. $0.8 \mu \mathrm{g}$ of plasmid DNA were transfected into Huh-7 cells which were seeded in 24-well plates at approximately 60\% confluence and $10 \mu \mathrm{mg}$ of plasmid DNA were injected into the tail veins of BALB/C mice. Each group included 10 mice. (A) Titers of HBsAg (ng/ml) and HBeAg (NCU/ml, National Clinical Unit/ml, in the supernatants of pBS-HBV1.1 $1_{B}, \mathrm{pBS}-\mathrm{HBV} 1.2_{\mathrm{B}}$ and $\mathrm{pBS}-\mathrm{HBV} 1.3_{\mathrm{B}}$ transfected Huh-7 cells at $48 \mathrm{~h}$ post-transfection. The data were analyzed by one-way ANOVA, and the differences were statistically significant ( ${ }^{*}$ and ${ }^{\Delta}$ mean $p<0.01$ ). (B) Real-time PCR detection of HBV DNA in mouse sera at day 7 after $\mathrm{HI}$ of pBS-HBV1.1 $1_{B}, \mathrm{pBS}-\mathrm{HBV} 1.2_{B}$ and $\mathrm{pBS}-\mathrm{HBV} 1.3_{B}$ (the number of the mice $\geq 3$ ). The data were analyzed by one-way ANOVA, and the differences were statistically significant ${ }^{*}$ means $p<0.01$ ). (C) Immunohistochemical staining of the liver sections for HBCAg in

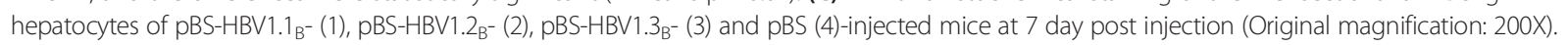

levels in the culture supernatant of pBS-HBV1.3 transfected Huh-7 cells were significantly higher than those with the of pBS-HBV1.1 $1_{\mathrm{B}}$ and $\mathrm{pBS}-\mathrm{HBV} 1.2_{\mathrm{B}}$ plasmids $(\mathrm{p}<0.01)$.

To further compare the replication competence of pBS-HBV1.1 $1_{\mathrm{B}}, \mathrm{pBS}-\mathrm{HBV} 1.2_{\mathrm{B}}$ and $\mathrm{pBS}-\mathrm{HBV} 1.3_{\mathrm{B}}$ in vivo, $\mathrm{BALB} / \mathrm{c}$ mice were subjected to $\mathrm{HI}$ with these plasmids. Each group contained 10 mice. At 7 dpi, mouse serum samples were collected for HBV DNA quantification. The liver tissue was collected for immunohistochemical staining of HBcAg. Figure $1 \mathrm{~B}$ showed that HI with pBSHBV $1.3_{B}$ resulted in a significantly higher HBV DNA level in mouse serum samples compared with HI with
pBS-HBV1.1 $1_{\mathrm{B}}$ and $\mathrm{pBS}-\mathrm{HBV} 1.2_{\mathrm{B}} \quad(\mathrm{p}<0.01)$. Immunostaining of $\mathrm{HBcAg}$ demonstrated that $\mathrm{HBcAg}$ positive hepatocytes could be detected in the mouse liver after HI with each of the three plasmids but absent in the control mice. Moreover, the $\mathrm{HBcAg}$ positive hepatocytes were most abundant in the mouse liver of pBS-HBV1.3 transfected mice (Figure 1C).

\section{The influence of the host genetic background and} plasmid backbone on HBV persistence

It is reported that HBV persistence after $\mathrm{HI}$ in mice depends on the host genetic background and plasmid backbone [12]. 
Firstly, the 1.3 fold over-length $\mathrm{HBV}$ genome was cloned into pAAV vector to generate pAAV-HBV1.3 $3_{\mathrm{B}}$. $\mathrm{HI}$ with pAAV-HBV1.3 $3_{\mathrm{B}}$ was performed in $\mathrm{C} 57 \mathrm{BL} / 6$ mice to examine whether this HBV isolate of genotype $B$ is able to establish persistent replication in vivo. In parallel, pAAV-HBV1.2 described by Huang et al. (2006) was used as a reference. pAAV-HBV1.3 group included 14 mice and pAAV-HBV1.2 group included 9 mice. The serum HBV DNA levels in C57BL/6 mice with pAAVHBV $1.3_{B}$ were determined at the indicated time points up to week 48 and were higher than those in mice with pAAV-HBV1.2 (Figure 2A).

The liver tissue was collected from C57BL/6 mice injected with pAAV-HBV1.3 $3_{\mathrm{B}}$ at 70, 168 and $252 \mathrm{dpi}$ or pAAV-HBV1.2 at $70 \mathrm{dpi}, 168 \mathrm{dpi}$ and $340 \mathrm{dpi}$. HBV DNA was extracted from the liver tissue samples and assayed for HBV DNA by Southern blot analysis. Bands corresponding to the expected size of the input HBV plasmids and HBV replication intermediates including relaxed circular (RC) and single-stranded (SS) HBV DNAs could be detected in the liver of HBsAg-positive C57BL/6 mice hydrodynamically injected with pAAVHBV1.3 $3_{B}$ or pAAV-HBV1.2 (Figure 2B). HBV replication intermediates were at a higher level in mice injected with pAAV-HBV1.2 than in those with pAAV-HBV1.3 $3_{\text {. }}$ Intrahepatic HBV DNA levels also detected by real-time PCR and the results were consistent with the Southernblot results (Figure 2C). Immunohistochemical staining of the liver sections for $\mathrm{HBcAg}$ revealed that both cytoplasmic and nucleic $\mathrm{HBcAg}$ were detected in the liver of HBsAg-positive mice hydrodynamically injected with pAAV-HBV1.3 $3_{\mathrm{B}}$ or pAAV-HBV1.2 (Figure 2D). In contrast, no $\mathrm{HBcAg}$ positive cell was present in the liver of the control mice and HBsAg-negative mice. All results obtained in this experiment indicate that $\mathrm{HBV}$ genotype $\mathrm{B}$ construct was replication competent in the mouse liver.

To investigate whether the vector backbone and the host genetic background also influence persistence of the HBV isolate of genotype B, $10 \mu \mathrm{g}$ of the pBS-HBV1.3 or pAAV-HBV1.3 $3_{B}$ plasmids were injected hydrodynamically into the tail veins of male $\mathrm{C} 57 \mathrm{BL} / 6$ or BALB/c mice. Each group included 5 mice. After $\mathrm{HI}$, the mice were regularly bled and the temporal changes in HBsAg, $\mathrm{HBeAg}, \mathrm{HBcAb}, \mathrm{HBsAb}$ and HBV DNA levels were monitored. In $\mathrm{BALB} / \mathrm{c}$ mice injected with $\mathrm{pBS}-\mathrm{HBV} 1.3_{\mathrm{B}}$, the HBsAg level increased in the first three days but dropped quickly afterward and all mice became negative at 1 wpi. However, the $\mathrm{HBs} A g$ level in BALB/c mice injected with pAAV-HBV1.3 $3_{B}$ declined slowly with time and $75 \%$ of the mice were $\mathrm{HBsAg}$ positive at day $10 \mathrm{dpi}$. HBsAg became undetectable in all mice at 4 wpi (Figure 3A). In contrast to $\mathrm{BALB} / \mathrm{c}$ mice, the $\mathrm{HBs}$ Ag level decreased much more slowly after injection of the same plasmids in C57BL/6 mice. $50 \%$ of C57BL/6 mice injected with pBS-HBV1.3 were $\mathrm{HBsAg-positive} \mathrm{at} 1 \mathrm{wpi}$ and all mice became negative at 2 wpi. Moreover, $75 \%$ of C57BL/6 mice injected with pAAV-HBV1.3 $3_{\mathrm{B}}$ were still $\mathrm{HBsAg}$-positive at 2 wpi. $\mathrm{HBsAg}$ remained detectable in $50 \%$ of the mice after 10 weeks (Figure $3 \mathrm{~A})$. These results confirmed that the host genetic background as well as the vector backbone influenced HBV persistence.

In addition, we also compared the kinetics of viremia between pAAV-HBV1.3 $3_{\mathrm{B}}$ and pAAV-HBV1.2 in the $\mathrm{HI}$ C56BL/6 mouse model. The serum HBV DNA level in pAAV-HBV1.3 $3_{B}$ injected mice was higher than that in pAAV-HBV1.2 injected mice (Figure 2A). However, the C57BL/6 mice received pAAV-HBV1.3 $3_{\mathrm{B}}$ had a lower positive rate of $\mathrm{HBsAg}$ compared with that received pAAVHBV1.2. 20\% of the mice are HBsAg positive at week 24 after $\mathrm{HI}$ with pAAV-HBV1.3 $3_{\mathrm{B}}$, which was only half of that in mice injected with pAAV-HBV1.2 (Figure 3B).

None of the C57BL/6 mice injected with pAAV-HBV1.2 produced HBsAb after $28 \mathrm{dpi}$, although all of them produced $\mathrm{HBcAb}$ after the day 7 (Table 1). However, 3 of $14 \mathrm{C} 57 \mathrm{BL} / 6$ mice received $\mathrm{pAAV}-\mathrm{HBV} 1.3_{\mathrm{B}}$ produced $\mathrm{HBsAb}$ after the 28 dpi. Moreover, the raise of HBsAb in pAAV-HBV1.3 $3_{B}$ injected mice was faster than that in pAAV-HBV1.2. As shown in Table 1, for those mice producing $\mathrm{HBsAb}$, they were $\mathrm{HBsAg}$ negative. All mice developed $\mathrm{HBcAb}$ after 7 dpi. Thus, different replication competent HBV genomes in the AAV vector may differ in their ability to establish the persistent replication in mice.

Impaired HBCAg specific cellular immunity in pAAV-HBV1.2 and pAAV-HBV1.3 ${ }_{B}$ injected C57BL/6 mice during initial activation

Huang et al. (2006) confirmed that the tolerance toward HBV surface antigen in this model was due to an insufficient cellular immunity against hepatitis B core antigen. To confirm this result, HBV-specific CTL responses against full length $\mathrm{HBcAg}$ peptide were detected at $3 \mathrm{dpi}$ and $10 \mathrm{dpi}$ after $\mathrm{HI}$ by ELISPOT assay of IFN- $\gamma$ producing cells. At 3 dpi we almost could not detect any significant levels of $\mathrm{HBcAg}$ specific IFN $\gamma$-producing cells in the splenocytes (Figure 4A). However, the average number of IFNy secreting cells was 463 and 653 in $1 \times 10^{6}$ splenocytes in pAAV-HBV1.2 and pAAV-HBV1.3 injected mice at $10 \mathrm{dpi}$, respectively (Figure $4 \mathrm{~B}$ ). There is no significant difference between those two groups $(\mathrm{p}>0.05)$. The result indicates that $\mathrm{HBcAg-specific}$ immune response may play a key role in clearing $\mathrm{HBV}$ infection at early stage in the HI mouse model.

\section{HBxi285 inhibited HBV replication in vitro}

To apply RNAi in vivo, the vector based expression of siRNAs was explored in the HI mouse model. For these 



C

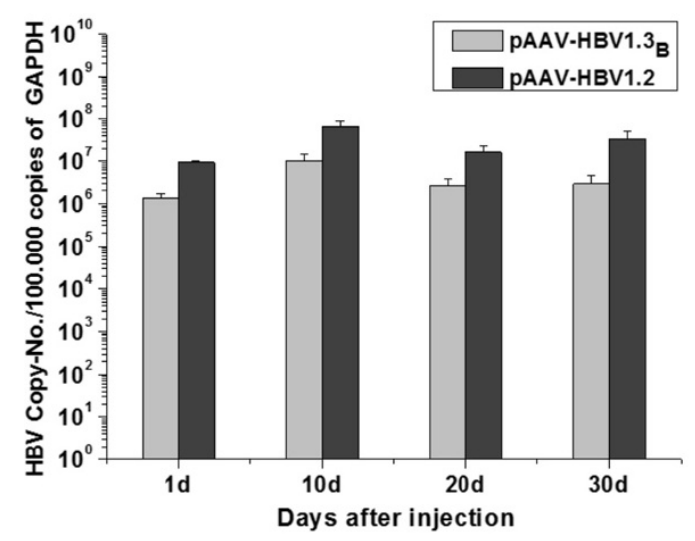

D
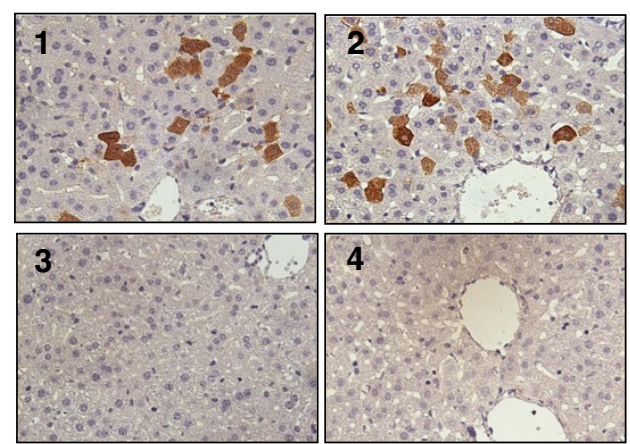

Figure $\mathbf{2}$ (See legend on next page.) 
(See figure on previous page.)

Figure 2 HBV replication and gene expression in vivo after $\mathrm{HI}$ with pAAV-HBV1.3 ${ }_{B}$ or pAAV-HBV1.2. $10 \mu \mathrm{g}$ of $\mathrm{pAAV}-\mathrm{HBV} 1.3_{\mathrm{B}}$ or $\mathrm{pAAV-HBV1.2}$ were injected into the tail veins of C57BL/6 mice. PAAV-HBV1.3 group included 14 mice and pAAV-HBV1.2 group included 9 mice. (A) Real-time detection of HBV DNA in mouse sera at the indicated time points (the number of the mice $\geq 3$ ). (B) Southern blot analysis with 20 mg of total DNA extracted from liver tissues of the mice HI with pAAV-HBV1.3 or pAAV-HBV1.2 at different time points after HI. All DNA samples were treated with RNase before subjected to agarose gel electrophoresis. Bands corresponding to the expected size of the input HBV plasmids, relaxed circular (RC) and single-stranded (SS) HBV DNAs are indicated. (C) Real-time PCR detection of HBV DNA levels in the liver of the mice after HI. (D) Immunohistochemical staining of the liver sections for HBcAg in hepatocytes of HBsAg-positive or HBsAg-negative mice at day 252 after HI with pAAV-HBV1.3B (1, HBsAg positive mice and 3, HBsAg negative mice) and at day 340 after HI with pAAV-HBV1.2 (2, HBsAg positive mice and 4, HBsAg negative mice) (Original magnification: 400X).

purpose, two different vectors pSuper.retro (pSR) and pSuper.basic (pSB) were tested. Two different target sequences in the HBV $x$ gene were selected and cloned into the vectors (see Material and Methods).

The antiviral effect of pSR-HBxi314 and pSR-HBxi285 was investigated in vitro. As shown in Figure $5 \mathrm{~A}$, the HBsAg and HBeAg levels decreased by $80.2 \%$ and $78.7 \%$ when pAAV-HBV1.3 $3_{\mathrm{B}}$ and pSR-HBxi285 were cotransfected into Huh-7 cells, respectively. However, when pAAV-HBV1.3 $3_{B}$ and pSR-HBxi314 were co-transfected into Huh-7 cells, the HBsAg and HBeAg levels were only inhibited by $10.5 \%$ and $30.3 \%$, respectively. Different concentrations of pSR-HBxi285 were used to test whether the antiviral effect was dose-dependent. Figure $5 \mathrm{~B}$ and $\mathrm{C}$ showed that pSR-HBxi285 inhibited HBsAg and HBeAg expression as well as HBV DNA in a concentrationdependent manner in the range of $0.1-0.5 \mu \mathrm{g}$. The $0.5 \mu \mathrm{g}$ dose of pSR-HBxi285 was most effective for the reduction of $\mathrm{HBsAg}, \mathrm{HBeAg}$ and $\mathrm{HBV}$ DNA in transient transfection.

To compare the antiviral effects of pSB-HBxi285 and pSR-HBxi285 in vitro, pAAV-HBV1.3 $3_{\mathrm{B}}$ and different concentrations of pSB-HBxi285 or pSR-HBxi285 were cotransfected into Huh-7 cells. Figure 5D shows that pSBHBxi285 and pSR-HBxi285 inhibited HBsAg and HBeAg in a dose-dependent manner. However, there was no significant difference in their antiviral effect $(\mathrm{P}>0.05)$.

\section{HBxi285 reduced serum HBsAg and HBV DNA levels in C57BL/6 mice after HI}

Based on the previous experiments, $10 \mu \mathrm{g}$ of pAAVHBV $1.3_{\mathrm{B}}$ and $10 \mu \mathrm{g}$ pSB-HBxi285 or pSR-HBxi285 were co-injected into $\mathrm{C} 57 \mathrm{BL} / 6$ mice to determine the antiviral effect of HBxi285 in vivo. Each group contained 10 mice. Initially, HBsAg levels in mice were significantly reduced by $\mathrm{HI}$ in the presence of pSB-HBxi285 or pSR-HBxi285 plasmids at $1 \mathrm{dpi}(\mathrm{p}<0.05)$, compared with the control groups receiving empty vectors (Figure 6A). However, the HBsAg levels in pSB-HBxi285 treated mice quickly increased during the follow up and reached the levels of the control at $14 \mathrm{dpi}$. In contrast, the HBsAg levels in pSR-HBxi285 treated mice were inhibited to a significantly lower degree before the $28 \mathrm{dpi}$ compared with the control groups $(\mathrm{p}<0.05)$. HBsAg became detectable in some mice at $42 \mathrm{dpi}$. It is worthy to note that the majority (7 of 10) of the mice received pSR-HBxi285 were HBsAg negative during the whole experimental period (Table 2). HBV DNA concentrations in mouse sera were determined and were well correlated with HBsAg levels (Figure 6B). Figure 6C shows that the HBsAg positive rate in pSB-HBxi285 or pSR-HBxi285 treated mice was significantly decreased in comparison to the controls at 1 dpi. Thereafter, the positive rate of HBsAg in pSBHBxi285 treated mice increased gradually and showed no significant difference in comparison to the control at 7 dpi. The positive rate of $\mathrm{HBsAg}$ in pSR-HBxi285 treated mice remained at a lower level (18.2-27.3\%) than other groups until the 4th week post injection (wpi) but showed similar levels to the other groups in the 5th wpi. Consistently, immunostaining of $\mathrm{HBcAg}$ in the liver section of mice after $\mathrm{HI}$ demonstrated that the co-application of pSR-HBxi285 or pBS-HBxi285 abolished $\mathrm{HBcAg}$ expression in the mouse liver at $3 \mathrm{dpi}$ (Figure 6D). However, HBcAg may become detectable in the mouse liver which received pSR-HBxi285 similar to those of control mice 4 weeks after HI. The results indicated that HBxi285 could significantly inhibit the HBsAg production and $\mathrm{HBV}$ replication. However the vector pSR-HBxi285 was more efficient in reducing HBsAg and HBV DNA levels than that of pSB-HBxi285.

\section{Discussion}

In the present study, an $\mathrm{HBV}$ genotype $\mathrm{B} \mathrm{HI}$ mouse model was established. After $\mathrm{HI}$ with pAAV-HBV1.3 ${ }_{\mathrm{B}}$, HBsAg and HBV DNA were detected in peripheral blood. Southern blot and immunohistochemical staining analysis revealed that $\mathrm{HBV}$ DNA and $\mathrm{HBcAg}$ were detected in the liver tissue of HBsAg-positive mice. Different hepatitis B virus genotypes may have distinct virologic characteristics, which may correlate with antiviral curative effects and clinical outcome [29,30]. The majority of HBV infections are distributed in the AsiaPacific region. In these regions, patients are mainly infected with genotypes B and C. Previous studies showed that in China and Taiwan, approximately $90 \%$ of patients under thirty-five years old who are infected with 


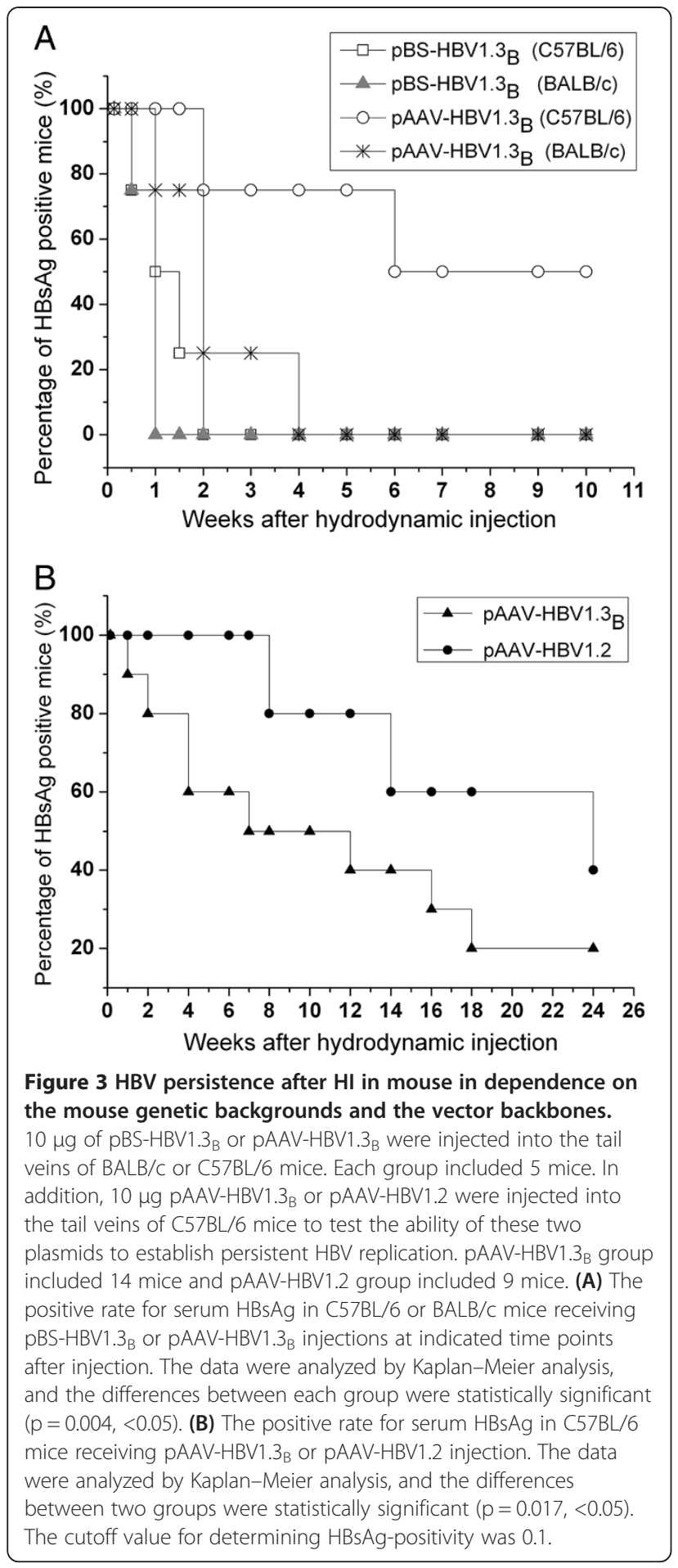

HBV would develop HCC and most of them carried an HBV genotype B infection [30,31]. Now, we have a system at hand to examine the replication of $\mathrm{HBV}$ genotype $\mathrm{B}$ clone in the mouse models.

In present study, we investigated the effect of the HBV genome length on HBV replication competence to find the optimal structure of replication competent HBV
Table 1 Appearance of anti-HBc and anti-HBs antibodies in C57BL/6 mice after $\mathrm{HI}$ of HBV plasmids

\begin{tabular}{lccccc}
\hline & \multicolumn{2}{c}{ Anti-HBc antibodies } & \multicolumn{3}{c}{ Anti-HBs antibodies } \\
\hline HBV clone & Day 1 & day 7 & Day 7 & Day 28 & Day 168 \\
pAAV-HBV1.3B & $0 / 14$ & $14 / 14$ & $0 / 14$ & $3 / 14$ & $6 / 8$ \\
pAAV-HBV1.2 & $0 / 9$ & $9 / 9$ & $0 / 9$ & $0 / 9$ & $4 / 8$
\end{tabular}

The number of $\mathrm{C} 57 \mathrm{BL} / 6$ mice in each group positive for anti-HBc or anti-HBs antibodies after injected hydrodynamically with $10 \mu \mathrm{g}$ of pAAV-HBV1.3 ${ }_{B}$ or pAAV-HBV1.2 plasmids. All the mice with HBsAb are HBsAg negative.

genotype B clone. Three clones with 1.1, 1.2 and 1.3 fold over length HBV genotype $B$ genomic DNA were constructed based on the pBluescript II KS (+) vector. Schematic representation of the 1.1, 1.2 and 1.3 fold HBV genome used in this study are shown in Additional file 1: Figure S1B. The plasmid with 1.3 fold genomes containing a complete extra copy of the entire EnhI, Enh II and $H B x$ gene as shown in Additional file 1: Figure S1B which is a suitable HBV construct for transfection and HI experiments. When the cloned plasmids were transfected into Huh-7 cells or hydrodynamically injected into BALB/c mice, pBS-HBV1.3 $3_{\mathrm{B}}$ demonstrated significantly high-level replication and gene expression in comparison to pBS-HBV $1.1_{\mathrm{B}}$ and pBS-HBV $1.2_{\mathrm{B}}$ (Figure 1). Increasing the length of the 1.3 fold over length HBV genome did not further improve the replication competence. Nevertheless, the replication competence declined and could not reach the original level of HBV in nature infection state when the length is less than 1.2 fold of the HBV genome. Durantel et al. and other groups used 1.1 fold over length HBV genome for studies on drug resistant HBV isolates [32,33]. However, they added strong foreign promoters to enhance the HBV transcription and replication. In conclusion, the 1.3 fold HBV genome length containing a complete extra copy of the entire EnhI, EnhII and HBx gene as described in the present study could be regarded as an optimal length for HBV replication constructs with the authentic HBV sequence, independent on a foreign promoter.

To establish a persistent replication $\mathrm{HBV}$ mouse model with the HBV genotype B clone, 1.3 fold over length $\mathrm{HBV}$ genotype $\mathrm{B}$ genome was sub-cloned into the pAAV-MCS vector and introduced into C57BL/6 mice by HI. Huang et al. (2006) found that the AAV vector contributed to the persistence of $\mathrm{HBV}$ in mouse liver. Therefore, we used a similar vector pAAV-MCS, to construct HBV genotype B replicational clone in this study. This vector also has the ITR (inverted terminal repeats) structure, which was considered as a key factor for its stable existence in vivo by integration or non-integration way. Because the vector does not express other proteins except that encoded by the target genes, the vector backbone has no direct effect on the immune system. 


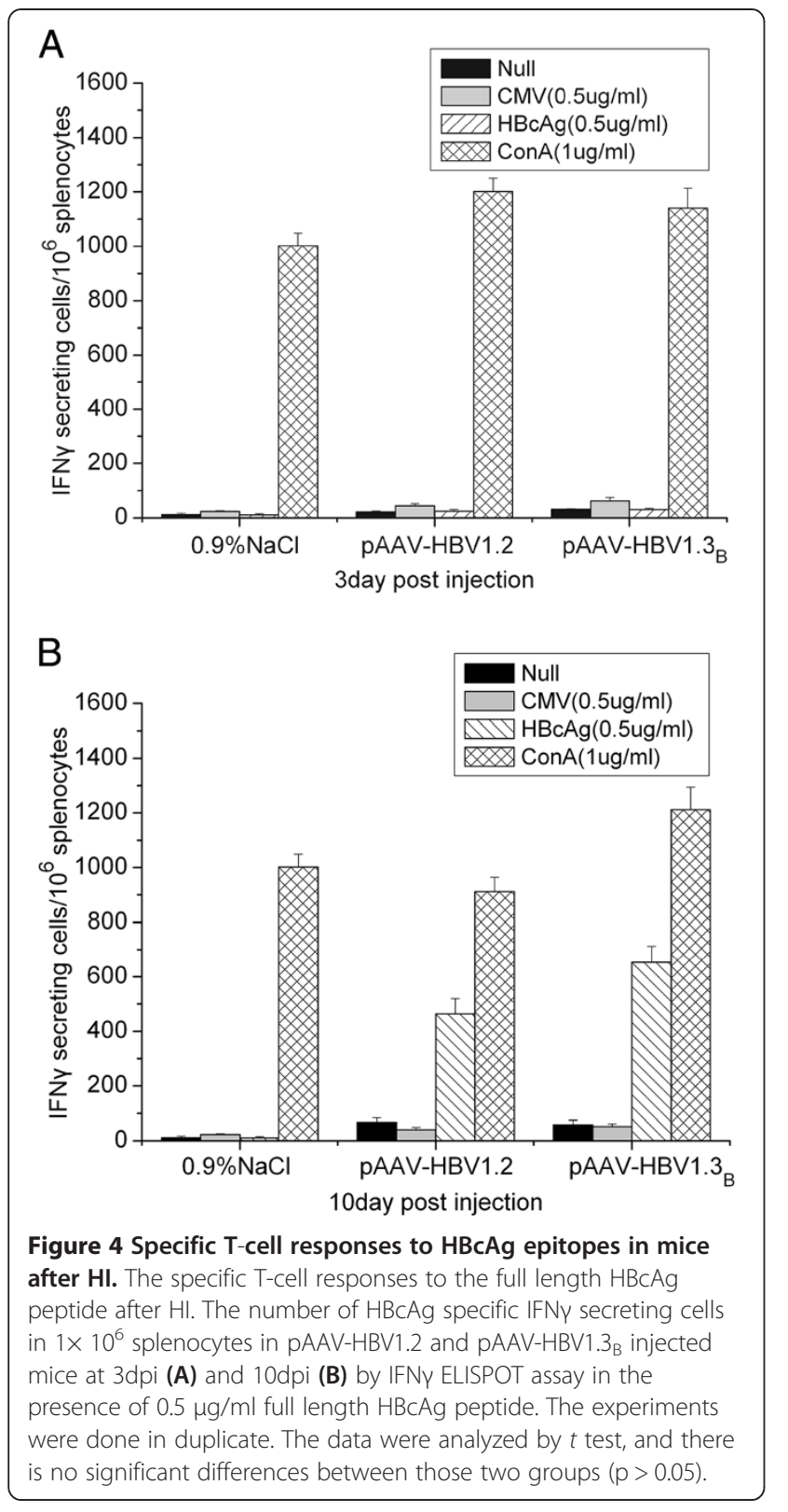

After HI, the mice presented higher HBV DNA level, but a lower positive rate for HBsAg in serum compared with pAAV-HBV1.2 injected mice [12]. Apparently, HBV replication is not strictly correlated with HBsAg production, as known for patients [34-38]. The result indicated that the model is more robust when pAAV-HBV1.2 genotype $\mathrm{A}$ is used as compared with pAAV-HBV1.3 $3_{\mathrm{B}}$. Huang et al. (2006) confirmed that the tolerance toward HBV surface antigen in this model was due to an insufficient cellular immunity against hepatitis B core antigen, as documented in humans. We repeated some experiments and obtained the same results (Figure 4A and B). The difference in plasmid backbones between both clones needs to be investigated further.
The antigenemia and production of $\mathrm{HBV}$ particles were highly reproducible in the persistent HBV replication mouse model based on HI making this model appropriate for the evaluation of the efficacy of anti-viral drugs. Therefore, we further investigated the anti-viral effect of vector-expressed $H B x$ siRNA in this model. Coapplication of the $H B x$ siRNA expression plasmids treatment of these mice induced a significant inhibition of HBV replication and expression. When pAAV-HBV1.3 was co-injected into the tail veins of $\mathrm{C} 57 \mathrm{BL} / 6$ mice with either pSB-HBxi285 or pSR-HBxi285, HBV expression and replication were efficiently inhibited. There are two methods commonly used to silence target genes. Chemical synthesized siRNAs have a good specificity and are commonly used on cells by transfection. However, such siRNAs, if not chemically modified, are instable and eliminated rapidly in vitro and in vivo. The production of siRNAs, particularly with specific chemical modifications, is very expensive. Another approach is to use siRNA transcription vectors. The disadvantages to use such as retroviral vectors are, for example, the lower transfection efficiency and slow action compared with chemical synthesized siRNA. However, the vector-based approach has some advantages regarding the stability and costs. It is important to prolong the expression of siRNAs to maintain the inhibition of HBV. Moreover, when the pSuper. Retro vector was transfected into a packaging cell line such as $293 \mathrm{~T}$ cell line, it could produce retroviral supernatants and obtain a higher rate of stable cell integration (The Manual of pSuper RNAi system, OligoEngine, Washington, USA) $[39,40]$.

HI of naked plasmid DNA is a simple yet effective in vivo gene delivery method into hepatocytes. The early reports suggested that a large portion of hepatocytes could be reached with this technique [41-44]. Therefore, it could be a useful method to test the efficacy of RNAi based antiviral therapies in the mouse model. Certainly, there is still a challenge how to transfer the knowledge gained in this system into human situation.

In this study, non-viral (pSuper.Basic) and retroviral vectors (pSuper.Retro) were used to construct shRNA (small hairpin RNA) expression plasmids [45] targeting the $H B x$ gene of $H B V$. The pSuper.Retro vector contains the $\mathrm{H} 1$ promoter which is a RNA polymerase III like promoter and can transcript shRNA steadily, and showed persistent inhibitory effect in vitro [46,47]. The pSuper.Retro vector includes $3^{\prime}$ and $5^{\prime}$ terminal LTR structure of murine stem cell virus. The pSuper.Retro vectors can be transfected into a packaging cell line to produce retroviral supernatants and obtain a higher rate of stable cell integration. In addition, this vector contains an incomplete packaging signal and could not produce recombinant retroviruses (The Manual of pSuper RNAi system, OligoEngine, Washington, USA). pSuper.Basic is 

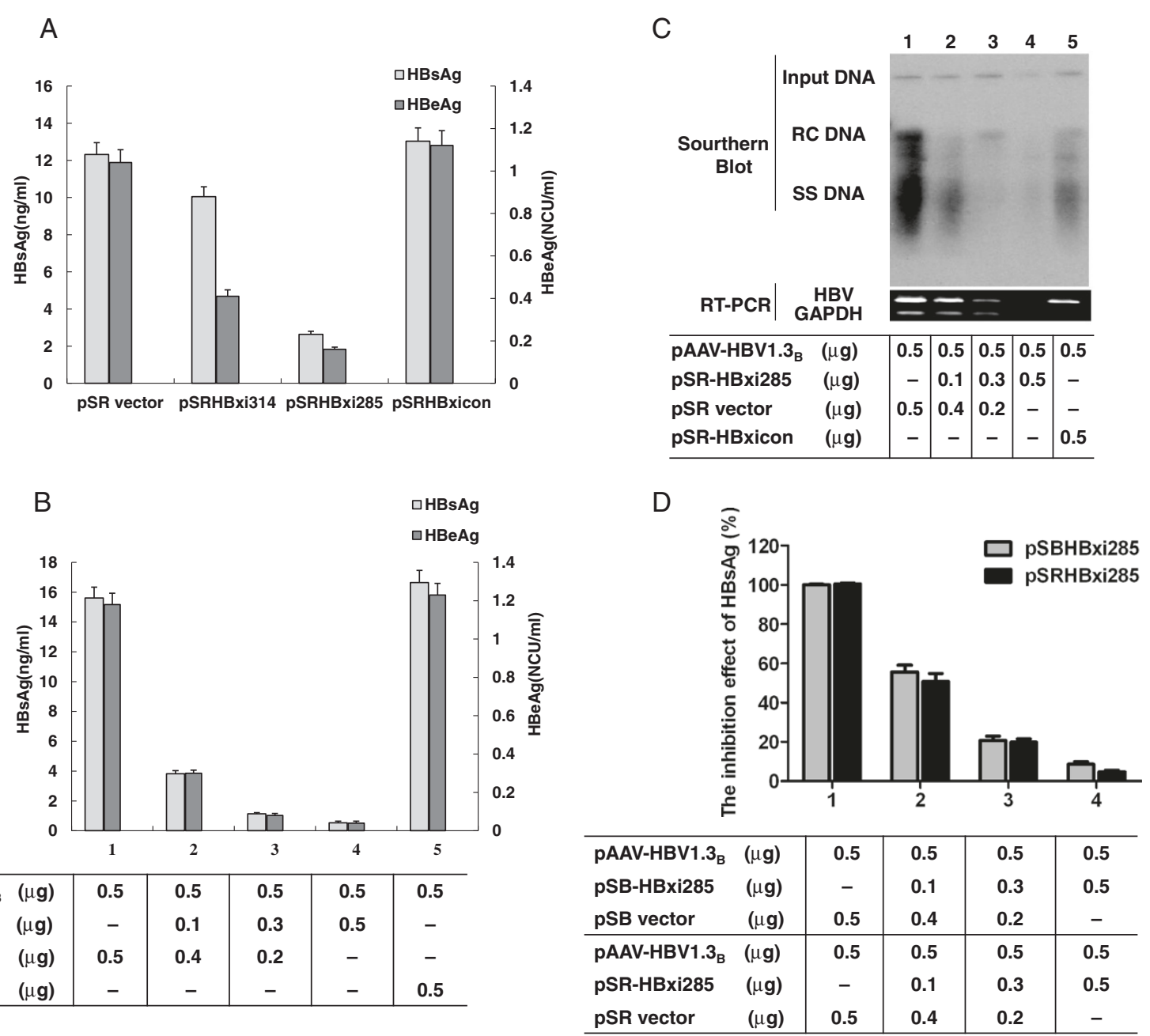

Figure 5 The effect of $H B x$ iRNA on HBV gene expression and replication in vitro. Different concentrations of HBX iRNA and PAAV-HBV1.3 were co-transfected into Huh-7 cells which were seeded in 24-well plates at approximately $60 \%$ confluence. The concentrations of the plasmids were indicated in the Tables. (A) HBsAg and HBeAg levels in the cell culture supernatants of cells co-transfected with $0.5 \mu \mathrm{g}$ of pAAV-HBV1.3-3 and $0.5 \mu \mathrm{g}$ of pSR-HBxi314- or pSR-HBxi285. (B) HBsAg and HBeAg levels in the cell culture supernatants of cells co-transfected with pAAV-HBV1.3B and 0, $0.1,0.3$, or $0.5 \mu \mathrm{g}$ of pSR-HBxi285. (C) HBV replicative intermediates in Huh-7 cells transfected with PAAV-HBV1.3B and 0, 0.1, 0.3, or 0.5 $\mu \mathrm{g}$ of pSRHBxi285. (D) A comparison of the inhibition rate of HBsAg in the cell culture supernatants of cells co-transfected with pAAV-HBV1.3-3-and pSB-HBxi285or pSR-HBxi285.

a pUC origin vector (The Manual of pSuper RNAi system, OligoEngine, Washington, USA) and used to compare the stability with pSuper.Retro in vivo. The difference of both vectors in the gene silencing effects is likely due to their stability in vivo. HBx protein plays an important role in HBV replication and HBV induced HCC $[26,48]$. Therefore, $H B x$ became a good target gene for gene silencing in recent years. Importantly, as all HBV RNA transcripts share the same sequence in the $H B x$ due to its unique transcription mechanism, siRNAs targeting the $H B x$ region actually knock down all $\mathrm{HBV}$ RNAs, as shown in the previous studies $[28,49,50]$.

The result showed that the siRNA targeting the region nt 285-303 of the $H B x$ coding region has a stronger antiviral effect than that targeting the region nt 314-
332. It is known that siRNA-specific features such as low G/C content, a bias towards low internal stability at the sense strand 3 '-terminus, lack of inverted repeats, and sense strand base preference, interaction with the cellular machinery called RISC and so on are likely to contribute to efficient RNAi process. The relative influence of these parameters is not fully understood and now under investigation by many groups [51-56]. When pAAV-HBV1.3 $3_{\mathrm{B}}$ and pSB-HBxi285 or pSR-HBxi285 was co-injected into the tail veins of C57BL/6 mice, HBV expression and replication could be significantly inhibited by the first week. Thereafter, the antiviral effect declined in the pSB-HBxi285 treated mice, whereas the antiviral effect of pSR-HBxi285 was maintained for at least 4 weeks. These results indicated that the retroviral 


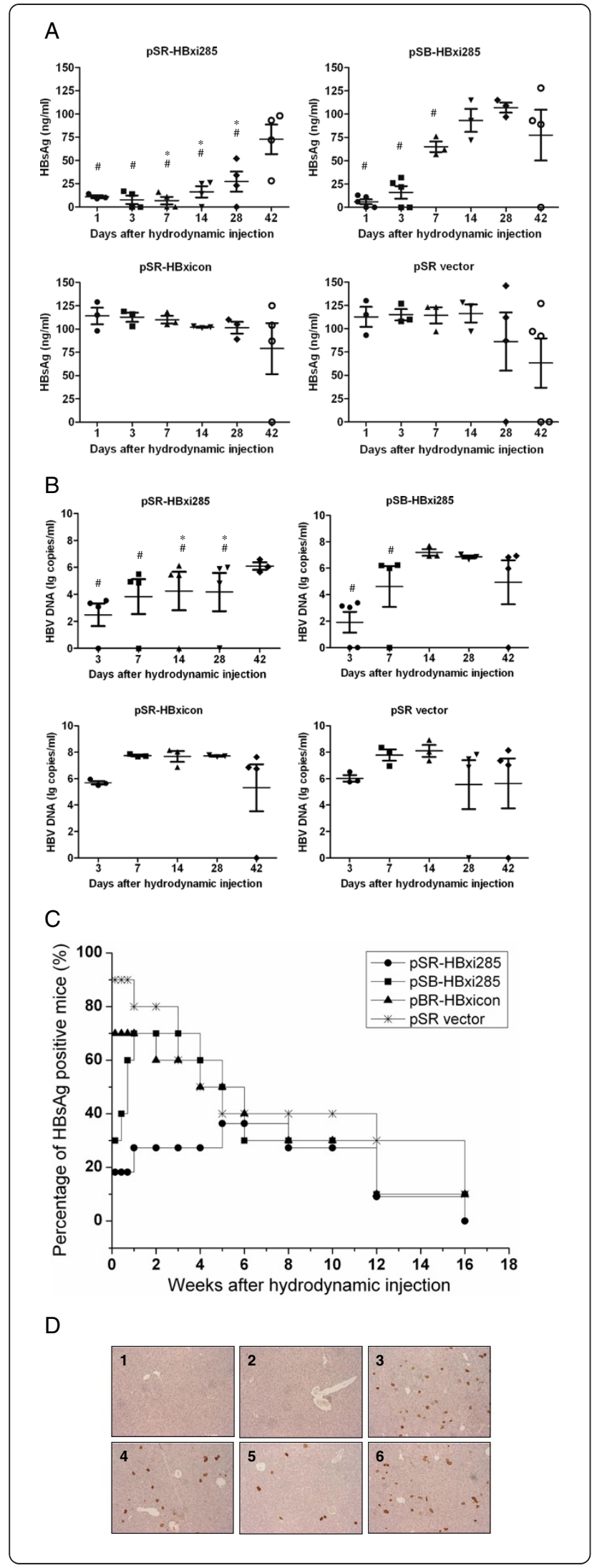

Figure 6 The effect of HBxi285 on HBV gene expression and replication in vivo. $10 \mu \mathrm{g}$ pAAV-HBV1.3 ${ }_{B}$ and $10 \mu \mathrm{g}$ pSB-HBxi285, pSR-HBxi285 or control plasmids were co-injected into the tail veins of C57BL/6 mice. Each group included 10 mice. (A) HBsAg levels, (B) HBV DNA and (C) the positive rate of HBsAg in the serum of C57BL/ 6 mice treated with PAAV-HBV1.3 and pSR-HBxi285 or pSB-HBxi285. Value 0 of HBV DNA means the copy number of HBV DNA is lower than detection limit. The data were analyzed by one-way ANOVA, and the differences were statistically significant $(\#: p<0.05$ pSRHBxi285 group vs. pSR-HBxicon group; ${ }^{*}: p<0.05$ pSR-HBxi285 group vs. pSB-HBxi285 group by one-way ANOVA) (D) Immunohistochemical staining for HBCAg in hepatocytes of C57BL/6 mice treated with pSR-HBxi285, pSB-HBxi285, pSR-HBxicon or pSR vector separately at 3 day post injection (1-4) and C57BL/6 mice treated with pSR-HBxi285 or pSR-HBxicon in the 4th wpi (5-6) (Original magnification: 200X).

vector based $H B x$ siRNA expression plasmid could much more effectively inhibit HBV expression and replication than the non-viral vector based $H B x$ siRNA expression plasmids. Among the mice which received pSR-HBxi285, HBV replication was completely suppressed in the majority of mice, as no HBsAg was detectable for the whole experimental period of 16 weeks. However, HBV gene expression and replication may resume in some mice despite an initial delay, indicating that transient suppression of HBV replication by $H B x$ siRNA may also fail to clear HBV completely in some individuals. It is worth to mention that the change of serum HBsAg and HBV DNA in the mice after the application with $H B x$ siRNAs occurred with different kinetics. The reason may be the different requirement of HBsAg translation and HBV DNA replication. It is well established that only a small fraction of HBsAg is required for virion production [57]. In the patients with chronic HBV infection, HBV DNA loads do not correlated with HBsAg [58]. Our results suggest that measures to prolong the antiviral effect of the siRNA should be investigated in future studies.

\section{Conclusions}

In summary, our established HBV genotype B HI mouse model is reliable and could be applied for studies on genetic and antiviral research of chronic HBV infection. The retroviral vector based $H B x$ siRNA expression plasmids could efficiently inhibit HBV expression and replication, suggesting that an siRNA-based treatment strategy may be an additional therapeutic option for future clinical use in patients with chronic HBV infection.

\section{Materials and methods}

\section{Construction of replication competent HBV genotype B} clones

The plasmid pAAV-HBV1.2 which contains an 1.2 fold over-length HBV genotype A genome (nt 1400-3182-1987) 
Table 2 HBsAg detection in HBxi285 treated and control mice

\begin{tabular}{lccc}
\hline Mouse group & Persistent negative & ${\text { Negative } \rightarrow \text { positive }^{\mathbf{a}}}^{\text {persistent positive or positive } \rightarrow \text { negative }^{\mathbf{b}}}$ \\
\hline pSR-HBxi285 & $7 / 10$ & $2 / 10$ & $1 / 10$ \\
pSB-HBxi285 & $3 / 10$ & $4 / 10$ & $3 / 10$ \\
pSR-HBxicon & $3 / 10$ & $0 / 10$ & $7 / 10$ \\
pSR vector & $1 / 10$ & $0 / 10$ & $9 / 10$
\end{tabular}

a Those mice with initial negative $\mathrm{HBsAg}$ became $\mathrm{HBsAg}$ positive. ${ }^{\mathrm{b}}$ Those mice with initial positive $\mathrm{HBsAg}$ became $\mathrm{HBsAg}$ negative during the whole experimental period of 16 weeks after $\mathrm{HI}$. The cutoff value for determining HBsAg-positivity was 0.1.

[12], was kindly provided by Prof. Pei-Jer Chen. The plasmid pUC-HBV containing a full length genotype B HBV genome (1820-3215-1824 nt, GenBank accession number: AY220698.1) was kindly provided by Prof. Jiming Zhang (Fudan University, China). The construction procedure of pBS-HBV1.1 $1_{\mathrm{B}}$, pBS-HBV1.2 $2_{\mathrm{B}}$ and pBS-HBV1.3 $3_{\mathrm{B}}$ is shown in Additional file 1: Figure S1A. First, the large fragments of the genotype B HBV DNA nt 1658-3215-247, nt 13603215-247 and nt 1040-3215-247 were amplified by PCR with primers $h b v 1.1 \mathrm{LF}$ (tagged with PstI site) and $h b v \mathrm{LR}$ (tagged with $X b a \mathrm{I}$ site), $h b v 1.2 \mathrm{LF}$ (tagged with PstI site) and $h b v \mathrm{LR}, h b v 1.3 \mathrm{LF}$ (tagged with PstI site) and $h b v \mathrm{LR}$, rsepectively. Those three fragments were inserted into the pBluescript II KS (+) (Invitrogen, Camarillo, USA) vector digested with PstI and XbaI. The small fragment of HBV DNA nt 247-1986 was amplified using primers $h b v S F$ (tagged with $X b a I$ site) and $h b v S R$ (tagged with SacI site), and was inserted into the the pBluescript II KS (+) vector digested with $\mathrm{XbaI}$ and $\mathrm{SacI}$. The resulting plasmids including nt 1658-3215-1986, nt 1360-3215-1986 and nt 1040-3215-1986 of HBV genome were named as pBSHBV $1.1_{\mathrm{B}}, \mathrm{pBS}-\mathrm{HBV} 1.2_{\mathrm{B}}$ and pBS-HBV1.3 ${ }_{\mathrm{B}}$, respectively. Schematic representation of the 1.1, 1.2 and 1.3 fold HBV genome are shown in Additional file 1: Figure S1B. All primers used to amplify $\mathrm{HBV}$ fragments are listed in Table 3. All DNA fragments in the final transfer vectors were amplified with Pyrobest DNA polymerase (TAKARA, Dalian, China) and cloned into the commonly used, commercially available pGEM-T vector (Promega, Madison, USA) for PCR cloning and sequencing. The correctness of the sequences of cloned DNA fragments were confirmed by sequencing. To establish $\mathrm{HI}$ mouse model with a high positive rate of $\mathrm{HBsAg}$, we cloned the 1.3 fold HBV genome into the vector including the backbone of adeno-associated virus, similar to the described procedure [12]. The HBV 1.3 fold over length genome DNA was amplified from pGEM-HBV1.3 $3_{B}$ with primers $h b v 1.3 \mathrm{~F}$ (tagged with NotI) and $h b v 1.3 \mathrm{R}$ (tagged with NotI), and sub-cloned into the NotI site of the pAAVMCS vector (Agilent technologies, La Jolla, USA). The resulting plasmid was designated as pAAV-HBV1.3 $3_{\mathrm{B}}$. The construction procedure of pAAV-HBV1.3 $3_{\mathrm{B}}$ is shown in Additional file 1: Figure S1C.

\section{Cell culture and transfection}

Huh-7 cells (Human hepatocarcinoma cell line) were maintained in 1640 medium supplemented with $10 \%$ of fetal bovine serum, $100 \mu \mathrm{g} / \mathrm{ml}$ penicillin and $100 \mu \mathrm{g} / \mathrm{ml}$ streptomycin. Cells were seeded in 24-well plates at approximately $60 \%$ confluence. After $24 \mathrm{~h}$, cells were transfected with Lipofectamine 2000 (Invitrogen, Camarillo, USA) according to the manufacturer's instructions. For pBS-HBV1.1 $1_{\mathrm{B}}$, pBS-HBV1.2 $2_{\mathrm{B}}$ and pBS-HBV1.3, $0.8 \mu \mathrm{g}$ of plasmid DNA and $2 \mu \mathrm{l}$ of lipofectamine 2000 were placed in each well of a 24-well plate. The efficiency of our transfection procedure was verified and controlled by transfection of a GFP expressing vector, as described previously [59].

To prove the antiviral effect of $H B x$ siRNA, $0.5 \mu \mathrm{g}$ of pAAV-HBV1.3 $3_{B}$ and $0.5 \mu \mathrm{g}$ of pSR-HBxi314 or pSRHBxi285 were co-transfected into Huh-7 cells. The dose dependent antiviral effect of pSR-HBxi285 was tested by co-transfection of $0.5 \mu \mathrm{g}$ pAAV-HBV1.3 ${ }_{\mathrm{B}}$ with $0,0.1,0.3$ and $0.5 \mu \mathrm{g}$ of pSR-HBxi285 into Huh-7 cells. To compare the antiviral effects of pSB-HBxi285 and pSR-

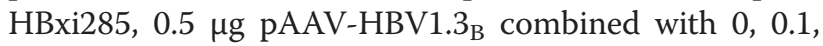
0.3 and $0.5 \mu \mathrm{g}$ of $\mathrm{pSB}-\mathrm{HBxi} 285$ or $\mathrm{pSR}-\mathrm{HBxi} 285$ were co-transfected into Huh-7 cells in parallel. All cell transfection experiments were performed three times.

\section{HI experiments}

The replication competence of the overlength $\mathrm{HBV}$ genomes in vivo was tested by $\mathrm{HI}$ with $\mathrm{pBS}-\mathrm{HBV} 1.1_{\mathrm{B}}$, pBS-HBV1.2 $2_{B}$ or pBS-HBV1.3 $3_{B}$ plasmids in BALB/C mice (female, 6-8 weeks old, from the breeding colonies of the experimental animal center in Hubei Province, China), with 10 mice per group. C57BL/6 mice (male, 6-8 weeks old, from the breeding colonies of the experimental animal center in Shanghai, China), were subjected to $\mathrm{HI}$ with pAAV-HBV1.3 $3_{\mathrm{B}}$ or pAAV-HBV1.2 to test the ability of these plasmids to establish persistent $\mathrm{HBV}$ replication. pAAV-HBV1.3 $\mathrm{B}$ group included 14 mice and pAAV-HBV1.2 group included 9 mice. To investigate the factors affecting $\mathrm{HBV}$ persistent in the mouse liver, we injected pBS-HBV1.3 $3_{\mathrm{B}}$ or $\mathrm{pAAV}-\mathrm{HBV} 1.3_{\mathrm{B}}$ into BALB/c or C57BL/6 mice separately, with 5 mice per group. HI experiments were carried out as described previously [17], 
Table 3 Primers for amplification of 1.3, 1.2, and 1.1 fold over length HBV replication-competent clones

\begin{tabular}{llll}
\hline Primer & Position & Sequence & Reference $^{\mathbf{a}^{\prime}}$ \\
\hline hbv1.1LF & HBV 1658-1677 & $5^{\prime}$-aac tgc aga aga gga ctc ttg gac ttt c-3' & AY220698.1 \\
hbv1.2LF & HBV 1360-1379 & $5^{\prime}$-aac tgc aga gta tac atc att tcc atg g-3' & AY220698.1 \\
hbv1.3LF & HBV 1040-1058 & $5^{\prime}$-tgc aac tgc agt gga tat cct gct tta atg-3' & AY220698.1 \\
hbvLR & HBV 253-233 & $5^{\prime}$-gct cta gac tct gtg gta ttg tga-3' & AY220698.1 \\
hbvSF & HBV 247-264 & $5^{\prime}$-ggc tag tct aga ctc gtg gtg g-3' & AY220698.1 \\
hbvSR & HBV 1986-1969 & $5^{\prime}$-acc gag ctc tcg aat aga agg aaa gaa-3' & AY220698.1 \\
hbv1.3F & PGEM-T 4-39 & $5^{\prime}$-ata aga atg cgg ccg ccg at tgg gcc cga cgt cg-3' & X65308.2 \\
hbv1.3R & PGEM-T 117-81 & $5^{\prime}$-ata gtt tag cgg ccg cgt tgg gag ctc tcc cat atg-3' & X65308.2 \\
\hline
\end{tabular}

Restriction sites are shown in italics. The gene sequences included in the primers are indicated by underling. ${ }^{\text {a }}$ The Genbank accession numbers of the used reference sequences are given.

$10 \mu \mathrm{g}$ of HBV plasmid DNA was injected into the tail veins of mice in a volume of $0.9 \% \mathrm{NaCl}$, equivalent to $8 \%$ of the mouse body weight. The total volume was delivered within 5-8 s. For $H B x$ siRNA experiments, $10 \mu \mathrm{g}$ pAAVHBV1.3 $3_{B}$ and $10 \mu \mathrm{g}$ pSB-HBxi285, pSR-HBxi285 or control plasmids were co-injected into the $\mathrm{C} 57 \mathrm{BL} / 6$ mice. Each group included 10 mice. The control mice were injected only with the volume of $0.9 \% \mathrm{NaCl}$, equivalent to $8 \%$ of the mouse body weight.

\section{Detection of $\mathrm{HBsAg}, \mathrm{HBeAg}, \mathrm{HBsAb}$ and $\mathrm{HBcAb}$}

Culture supernatants of pBS-HBV1.1 $1_{B}, \mathrm{pBS}-\mathrm{HBV} 1.2_{\mathrm{B}}$ or pBS-HBV1.3 $3_{B}$ transfected Huh-7 cells were harvested at $48 \mathrm{~h}$ post-transfection. Mouse sera were collected at the $1 d$ (day), 3d, 7d, 10d, 2w (week), 3w, 4w, 5w, 6w, 7w, $8 \mathrm{w}, 9 \mathrm{w}, 10 \mathrm{w} .$. after HI. The analysis of HBsAg $(\mathrm{ng} / \mathrm{ml})$, $\mathrm{HBeAg}$ (NCU/ml, National Clinical Unit/ml), HBsAb (mIU/ml, Milli-International Units) and $\mathrm{HBcAb}$ (S/Co, Sample/Cutoff value) levels were determined by using the Architect system and CMIA kits (Abbott Laboratories, Wiesbaden-Delkenheim, DE) according to the manufacturer's instructions.

\section{Isolation and analysis of HBV DNA in mouse sera}

HBV DNA was extracted from $40 \mu \mathrm{l}$ of mouse serum samples. The protocol was described previously [17]: $40 \mu \mathrm{l}$ of samples were treated with $10 \mu \mathrm{g}$ DNase I for $16 \mathrm{~h}$ at $37^{\circ} \mathrm{C}$. $100 \mu \mathrm{l}$ of lysis buffer $(20 \mathrm{mM}$ Tris-HCl, $20 \mathrm{mM}$ EDTA, $50 \mathrm{mM} \mathrm{NaCl}$ and $0.5 \%$ SDS) containing $50 \mu \mathrm{g}$ proteinase $\mathrm{K}$ were added. After incubation at $65^{\circ} \mathrm{C}$ for $3 \mathrm{~h}$, viral DNA was isolated by phenol/chloroform extraction and ethanol precipitation. The DNA pellet was rinsed with $70 \%$ ethanol and resuspended in $10 \mu \mathrm{l}$ of $\mathrm{ddH}_{2} \mathrm{O}$.

The quantification of HBV DNA was performed by using a routine real time PCR procedure, described previously [34,60-64]. The HBV copy numbers were determined by SYBR Green Real time PCR Master Mix (commercially available assay kit, TOYOBO, Osaka, Japan). Melt curve analysis and agarose gel electrophoresis were used to verify the specificity of the real-time PCR. The following primers were used: forward primer: $5^{\prime}$-CTG CAT CCT GCT GCT ATG-3' (nt 408-425), reverse primer: 5' CAC TGA ACA AAT GGC AC-3' (nt 685-701) according to the reference sequence with Genbank accession number (AY220698.1). Serum containing a known concentration of HBV DNA was used as a positive control.

\section{Immunohistochemistry}

The liver tissue was taken from the mice receiving $\mathrm{HI}$ with pBS-HBV1.1 $1_{\mathrm{B}}$, pBS-HBV1.2 $2_{\mathrm{B}}$ or $\mathrm{pBS}-\mathrm{HBV} 1.3_{\mathrm{B}}$ at 7 day post injection (dpi) and the mice receiving $\mathrm{HI}$ with pAAV-HBV1.3 $3_{\mathrm{B}}$ at $70 \mathrm{dpi}, 168 \mathrm{dpi}$ and $252 \mathrm{dpi}$ or pAAV-HBV1.2 at $70 \mathrm{dpi}, 168 \mathrm{dpi}$ and $340 \mathrm{dpi}$, which was then used for immunohistochemical staining of the $\mathrm{HBcAg}$ in hepatocytes. The liver tissue of the mice received $0.9 \% \mathrm{NaCl}$ was used as negative control. Liver tissue was collected from the mice and embedded in paraffin. Intrahepatic $\mathrm{HBcAg}$ was visualized by immunohistochemical staining with rabbit anti-HBc (Dako) of the liver tissue sections. The liver tissue sections were also stained with hematoxylin.

\section{Purification and Southern blot analysis of HBV DNA from the liver tissue of mice}

Total DNA from the pAAV-HBV1.3 $3_{\mathrm{B}}$ and $H B x$ siRNA expression plasmids co-transfected Huh-7 cells and the liver tissue of mice was isolated using commercial kits (OMEGA, Norcross, USA). The isolated HBV DNA was subjected to agarose gel electrophoresis followed by denaturation and Southern blot analysis. All DNA samples were treated with RNase before gel electrophoresis. HBV DNA was detected by hybridization with a digoxigenin (DIG) (Roche, Lewes, UK)-labeled full length HBV probe. The hybridization signals were visualized on $\mathrm{x}$-ray film using an alkaline phosphatase-anti-DIG-Fab conjugate in the presence of the chemiluminescence substrate CDP-Star (Roche).

\section{Enzyme-Linked Immunospot (ELISPOT) assay}

ELISPOT assay was carried out using the mouse IFN- $\gamma$ precoated ELISPOT Kit (Dakewe, Shenzhen, China) 
according to the manufacturer's instructions. Briefly, 96well flat-bottomed microtiter plates were preincubated with the coating antibody (anti-IFN- $\gamma$ monoclonal antibody) at $4^{\circ} \mathrm{C}$ overnight and blocked for $2 \mathrm{hr}$ at $37^{\circ} \mathrm{C}$. Mouse splenocytes at the density of $1 \times 10^{6}$ cells per well were added to wells in triplicate with final concentration of $0.5 \mu \mathrm{g} / \mathrm{ml}$ full length HBcAg peptide (ProSpec, NessZiona, Israel) separately and incubated at $37^{\circ} \mathrm{C}, 5 \% \mathrm{CO}_{2}$ for $24 \mathrm{hr} .1 \mu \mathrm{g} / \mathrm{ml}$ of ConA (Sigma, St. Louis, USA) was used as positive control. Thereafter, cells were removed. Wells were washed ten times with PBS containing 0.05\% Tween-20 (PBS-T) and incubated with $100 \mathrm{ml}$ of biotinylated anti-IFN $\gamma$ antibody for $1 \mathrm{hr}$. The plates were washed again with PBS-T and incubated with $50 \mathrm{ml}$ HRP-streptoavidin solution at $37^{\circ} \mathrm{C}$ for $1 \mathrm{hr}$. Spot-forming cells were counted and analyzed with an ELISPOT plate reader (BioReader 4000, Biosys, Germany). Results were presented as spot-forming cells per $1 \times 10^{6}$ cells.

\section{Construction of $H B x$ siRNA expression plasmids}

Two pairs of DNA sequences targeting the nt 285-303 and nt 314-332 of the $H B x$ coding region of $\mathrm{HBV}$ (genotype $\mathrm{B}, \mathrm{adw}$ ) were designed in accordance with the protocols for the siRNA expression vectors pSuper.Basic and pSuper.Retro (OligoEngine, Washington, USA), and the two RNAi design server (http://www.ambion.com/ techlib/misc/siRNA_tools.html and http://www.dharmacon. com/DesignCenter). The DNA sequences were as follows: HBxi314F, 5'-GAT CCC CCG ACC GAC CTT GAG GCA TAT TCA AGA GAT ATG CCT CAA GGT CGG TCG TTT TTA-3', HBxi314R, 5'-AGC TTA AAA ACG ACC GAC CTT GAG GCA TAT CTC TTG AAT ATG CCT CAA GGT CGG TCG GGG-3'; HBxi285F, 5'-GAT CCC C GA GGA CTC TTG GAC TTT CAT TCA AGA GAT GAA AGT CCA AGA GTC CTC TTT T TA-3', HBxi285R, 5'-AGC TTA AAA AGA GGA CTC TTG GAC TTT CAT CTC TTG AAT GAA AGT CCA AGA GTC CTC GGG-3', the $H B x$ iRNA control sequences were: HBxiconF, $5^{\prime}$-GAT CCC CGC ACC TAT AAC AAC GGT AGT TCA AGA GAC TAC CGT TGT ATA GGT GCT TTT TA-3', HBxiconR, 5'-AGC TTA AAA AGC ACC TAT AAC AAC GGT AGT CTC TTG AAC TAC CGT TGT TAT AGG TGC GGG-3' (the sequences targeting $H B x$ gene are shown in italics). The single strand DNA products were purchased from Invitrogen (Shanghai, China).

The above complementary sequences were phosphorylated and ligated into BglII and HindIII digested pSuper.Basic or pSuper.Retro vector. The resulting plasmids were named as pSB-HBxi314, pSB-HBxi285, pSB-HBxicon, pSR-HBxi314, pSR-HBxi285 and pSRHBxicon. The clones were sequenced to confirm the correctness of the sequences.

\section{Statistical analysis}

The data were evaluated by Student's t-test or one-way ANOVA followed by Tukey's post hoc test. The statistical significance of the data was considered at $\mathrm{p}<0.05$.

\section{Approval of the ethics committee}

The animal experiments were carried out in concordance with the guidelines established by the Institutional Animal Care and Use Committee at the Huazhong University of Science and Technique and the Tongji Hospital of Tongji Medical College. The mice used in this study were anesthetized with ketamine and xylazine.

\section{Additional files}

\begin{abstract}
Additional file 1: Figure S1. Construction procedure for the pBS-HBV1.1 $1_{B}$ pBS-HBV1.2 $2_{B}$, pBS-HBV1.3 ${ }_{B}$ and PAAV-HBV1.3 ${ }_{B}$ vectors. (A) The fragments containing 1.1, 1.2 and 1.3 fold over length HBV genomes were amplified from the plasmid pUC-HBV containing a full length genotype B HBV genome (1820-3215-1824 nt, GenBank accession number AY220698.1) and inserted into the Pstl and Sacl sites of the plasmid pBluescript II KS (+). (B) Schematic representation of the 1.1,1.2 and 1.3 fold HBV genome used in this study are shown. HBV ORFs as well as enhancers are indicated in different patters. (C) The HBV 1.3 fold over length genome DNA was amplified from PGEM-HBV1.3 $3_{B}$ and sub-cloned into the Notl site of the PAAV-MCS vector

Additional file 2: Figure S2. Identification of pBS-HBV1.1 $1_{B}, p B S-H B V 1.2_{B}$ and $\mathrm{pBS}-\mathrm{HBV} 1.3_{\mathrm{B}}$. pBS-HBV1.1 $1_{\mathrm{B}}, \mathrm{pBS}-\mathrm{HBV} 1.2_{\mathrm{B}}$ and $\mathrm{pBS}-\mathrm{HBV} 1.3_{\mathrm{B}}$ were identified by restriction enzyme analysis. Lines 1/9: $1 \mathrm{~kb}$ DNA ladder; Lines 2-4: pBS-HBV1.1 $1_{B}$, pBS-HBV1.2 and pBS-HBV1.3 $3_{B}$ were digested with Pstl and SaCl respectively; Lines 5: pBluescriptll KS (+) was digested with Pstl and Sacl; Lines 6-8: pBS-HBV1.1 $1_{\mathrm{B}}, \mathrm{pBS}-\mathrm{HBV} 1.2_{\mathrm{B}}$ and pBS-HBV1.3 $3_{\mathrm{B}}$ were digested with Pstl.
\end{abstract}

Competing interests

The authors declare that they have no competing interests.

\section{Authors' contributions}

$L L, J S, D Y$, and $M L$ conceived and designed the experiments. $L L, J S, H S$, and $Z Z$ performed the experiments. $L L, J S, D Y$, and $M L$ analyzed the data. $A L, B W$, $X Z$, JW, JJW, DY, and ML contributed reagents/materials/analysis tools. JS, DY, and $M L$ wrote the paper. All authors read and approved the final manuscript.

\section{Acknowledgment}

This work was supported by grants from National Major Science and Technology Project for Infectious Diseases of China (2008ZX10002-011), State Major Basic Research Program of China (2005CB522901, 2007CB512804 and 2009CB522500), National Natural Science Foundation of China (30271170 and 81201289) and International Science \& Technology Cooperation Program of China (2011DFA31030) to D. Yang and grants of Deutsche Forschungsgemeinschaft (Transregio TRR60 and GK 1045/2) to M. Lu. We are grateful to Dr. Pei-Jer Chen for providing the vector PAAV-HBV1.2.

\section{Author details}

'Department of Infectious Diseases, Union Hospital of Tongji Medical College, Huazhong University of Science and Technology, Wuhan, P.R. China. ${ }^{2}$ Department of Infectious Disease, Anhui Provincial Hospital, No.9 Lujiang Road, Hefei, P.R. China. ${ }^{3}$ Division of Clinical Immunology, Tongji Hospital, Tongji Medical College, Huazhong University of Science and Technology, Wuhan, P.R. China. ${ }^{4}$ Animal Center, Tongji Hospital of Tongji Medical College, Huazhong University of Science and Technology, Wuhan, P.R. China. ${ }^{5}$ Institute of Virology, University Hospital of Essen, University Duisburg-Essen, Essen, Germany. 
Received: 26 March 2013 Accepted: 21 June 2013

Published: 28 June 2013

\section{References}

1. Lai CL, Ratziu V, Yuen MF, Poynard T: Viral hepatitis B. Lancet 2003, 362:2089-2094

2. Ganem D, Prince AM: Hepatitis B virus infection-natural history and clinical consequences. N Engl J Med 2004, 350:1118-1129.

3. Liaw YF, Chu CM: Hepatitis B virus infection. Lancet 2009, 373:582-592.

4. Kao JH: Molecular epidemiology of hepatitis B virus. Korean J Intern Med 2011, 26:255-261.

5. Guidotti LG, Matzke B, Schaller H, Chisari FV: High level hepatitis B virus replication in transgenic mice. J Virol 1995, 69:6158-6169.

6. Araki K, Miyazaki J, Hino O, Tomita N, Chisaka O, et al: Expression and replication of hepatitis $B$ virus genome in transgenic mice. Proc Natl Acad Sci USA 1989, 186:207-211.

7. Moriyama T, Guilhot S, Klopchin K, Moss B, Pinkert CA, et al: Immunobiology and pathogenesis of hepatocellular injury in hepatitis $B$ virus transgenic mice. Science 1990, 248:361-364.

8. Larkin J, Clayton M, Sun B, Perchonock CE, Morgan JL, et al: Hepatitis B virus transgenic mouse model of chronic liver disease. Nat Med 1999, 5:907-912.

9. Böcher WO, Marcus H, Shakarchy R, Dekel B, Shouval D, et al: Antigenspecific $B$ and $T$ cells in human/mouse radiation chimera following immunization in vivo. Immunology 1999, 96:634-641.

10. Ilan E, Burakova T, Dagan S, Nussbaum O, Lubin I, et al: The hepatitis B virus-trimera mouse: a model for human HBV infection and evaluation of anti-HBV therapeutic agents. Hepatology 1999, 29:553-562.

11. Dandri M, Burda MR, Török E, Pollok JM, Iwanska A, et al: Repopulation of the mouse liver with human hepatocytes and in vivo infection with hepatitis B virus. Hepatology 2001, 33:981-988.

12. Huang LR, Wu HL, Chen PJ, Chen DS: An immunocompetent mouse model for the tolerance of human chronic hepatitis $B$ virus infection. Proc Natl Acad Sci USA 2006, 103:17862-17867

13. Takehara T, Suzuki T, Ohkawa K, Hosui A, Jinushi M, et al: Viral covalently closed circular DNA in a non-transgenic mouse model for chronic hepatitis B virus replication. J Hepat 2006, 44:267-274.

14. Cobleigh MA, Buonocore L, Uprichard SL, Rose JK, Robek MD: A vesicular stomatitis virus-based hepatitis $B$ virus vaccine vector provides protection against challenge in a single dose. J Virol 2010, 84:7513-7522.

15. Lin YJ, Huang LR, Yang HC, Tzeng HT, Hsu PN, et al: Hepatitis B virus core antigen determines viral persistence in a $\mathrm{C} 57 \mathrm{BL} / 6$ mouse model. Proc Natl Acad Sci USA 2010, 107:9340-9345

16. Yang $\mathrm{PL}$, Althage $\mathrm{A}$, Chung J, Maier $\mathrm{H}$, Wieland S, et al: Immune effectors required for hepatitis B virus clearance. Proc Natl Acad Sci USA 2010, 107:798-802.

17. Yin Y, Wu C, Song J, Wang J, Zhang E, et al: DNA Immunization with Fusion of CTLA-4 to Hepatitis B Virus (HBV) Core Protein Enhanced Th2 Type Responsesand Cleared HBV with an Accelerated Kinetic. PLoS One 2011, 6:1-11.

18. Wu C, Deng W, Deng L, Cao L, Qin B, et al: Amino acid substitutions at the positions 122 and 145 of hepatitis B surface antigen ( $\mathrm{HBsAg}$ ) determine the antigenicity and immunogenicity of $\mathrm{HBsAg}$ and influence in vivo HBsAg clearance. J Virol 2012, 86:4658-4669.

19. Tillmann HL: Antiviral therapy and resistance with hepatitis B virus. World J Gastroenterol 2007, 13:125-140.

20. Zoulim F: Infection Hepatitis B virus resistance to antiviral drugs: where are we going? Liver Int 2011, Suppl 1:111-116.

21. Haasnoot PC, Cupac D, Berkhout B: Inhibition of virus replication by RNA interference. J Biomed Sci 2003, 10:607-616.

22. Randall G, Rice CM: Interfering with hepatitis $C$ virus RNA replication. Virus Res 2004, 102:19-25.

23. Wu J, Nandamuri KM: Inhibition of hepatitis viral replication by siRNA. Expert Opin Biol Ther 2004, 4:1649-1659.

24. Li BJ, Tang Q, Cheng D, Qin C, Xie FY, et al: Using siRNA in prophylactic and therapeutic regimens against SARS coronavirus in Rhesus macaque. Nat Med 2005, 11:944-951.

25. Tang H, Oishi N, Kaneko S, Murakami S: Molecular function and biological roles of hepatitis B virus x protein. Cancer Sci 2006, 97:977-983.

26. Wei $Y$, Neuveut $C$, Tiollais $P$, Buendia MA: Molecular biology of the hepatitis B virus and role of the X gene. Pathol Biol 2010, 58:267-272.
27. Bouchard MJ, Schneider RJ: The enigmatic $X$ gene of hepatitis $B$ virus. J Virol 2004, 78:12725-12734.

28. Meng Z, Qiu S, Zhang X, Wu J, Schreiter T, et al: Inhibition of woodchuck hepatitis virus gene expression in primary hepatocytes by siRNA enhances the cellular gene expression. Virology 2009, 384:88-96.

29. Tseng TC, Kao JH: HBV genotype and clinical outcome of chronic hepatitis B facts and puzzles. Gastroenterology 2008, 134:1272-1273.

30. Kao JH, Chen PJ, Lai MY, Chen DS: Hepatitis B genotypes correlate with clinical outcomes in patients with chronic hepatitis B. Gastroenterology 2000, 118:554-559.

31. Yuan J, Zhou B, Tanaka Y, Kurbanov F, Orito E, et al: Hepatitis B virus (HBV) genotypes/subgenotypes in china: mutations in core promoter and precore/core and their clinical implications. J Clin Virol 2007, 39:87-93.

32. Durantel D, Carrouée-Durantel S, Werle-Lapostolle B, Brunelle MN, Pichoud $C$, et al: A new strategy for studying in vitro the drug susceptibility of clinical isolates of human hepatitis B virus. Hepatology 2004, 40:855-864

33. Yang $H$, Westland $C$, Xiong $S$, Delaney WE: In vitro antiviral susceptibility of full-length clinical hepatitis B virus isolates cloned with a novel expression vector. Antiviral Res 2004, 61:27-36.

34. Lu M, Isogawa M, Xu Y, Hilken G: Immunization with the gene expressing woodchuck hepatitis virus nucleocapsid protein fused to cytotoxic-Tlymphocyte-associated antigen 4 leads to enhanced specific immune responses in mice and woodchucks. J Virol 2005, 79:6368-6376.

35. Kuhns MC, Kleinman SH, McNamara AL, Rawal B, Glynn S, et al: Lack of correlation between HBsAg and HBV DNA levels in blood donors who test positive for $\mathrm{HBsAg}$ and anti-HBc: implications for future HBV screening policy. Transfusion 2004, 44:1332-1339.

36. Manesis EK, Hadziyannis E, Angelopoulou OP, Hadziyannis SJ: Prediction of treatment-related $\mathrm{HBsAg}$ loss in $\mathrm{HBeAg}$-negative chronic hepatitis $\mathrm{B}$ : a clue from serum HBsAg levels. Antivir Ther 2007, 12:73-82.

37. Wiegand J, Wedemeyer $H$, Finger A, Heidrich B, Rosenau J, et al: A decline in hepatitis B virus surface antigen (hbsag) predicts clearance, but does not correlate with quantitative hbeag or HBV DNA levels. Antivir Ther 2008, 13:547-554

38. Simonetti J, Bulkow L, McMahon BJ, Homan C, Snowball M, et al: Clearance of hepatitis B surface antigen and risk of hepatocellular carcinoma in acohort chronically infected with hepatitis B virus. Hepatology 2010, 51:1531-1537.

39. Chen CC, Ko TM, Ma HI, Wu HL, Xiao X, et al: Long-term inhibition of hepatitis $B$ virus in transgenic mice by double-stranded adenoassociated virus 8-delivered short hairpin RNA. Gene Ther 2007, 14:11-19.

40. Yang Z, Zhang J, Cong $\mathrm{H}$ : A retrovirus-based system to stably silence GDF-8 expression and enhance myogenic differentiation in human rhabdomyosarcoma cells. J Gene Med 2008, 10:825-833.

41. Sebestyen MG, Budker VG, Budker T, Subbotin VM, Zhang G, Monahan $\mathrm{SD}$, et al: Mechanism of plasmid delivery by hydrodynamic tail vein injection. I. Hepatocyte uptake of various molecules. J Gene Med 2006, 8:852-873.

42. Crespo A, Peydro A, Dasi F, Benet M, Calvete JJ, Revert F, et al: Hydrodynamic liver gene transfer mechanism involves transient sinusoidal blood stasis and massive hepatocyte endocytic vesicles. Gene Ther 2005, 12:927-935.

43. Liu F, Lei J, Vollmer R, Huang L: Mechanism of liver gene transfer by mechanical massage. Mol Ther 2004, 9:452-457.

44. Kobayashi N, Nishikawa M, Hirata K, Takakura Y: Hydrodynamics-based procedure involves transient hyperpermeability in the hepatic cellular membrane: implication of a nonspecific process in efficient intracellular gene delivery. J Gene Med 2004, 6:584-592.

45. Zamore PD, Tuschl T, Sharp PA: RNAi: double-stranded RNA directs the ATP-dependent cleavage of mRNA at 21 to 23 nucleotide intervals. Cell 2000, 101:25-33

46. Baer M, Nilsen TW, Costigan C, Altman S: Structure and transcription of a human gene for $\mathrm{H} 1 \mathrm{RNA}$, the RNA component of human RNase P. Nucleic Acids Res 1990, 18:97-103.

47. Brummelkamp TR, Bernards R, Agami R: A System for Stable Expression of Short Interfering RNAs in Mammalian Cells. Science 2002, 296:550-553.

48. Cougot D, Neuveut C, Buendia MA: HBV induced carcinogenesis. J Clin Virol 2005, 34(suppl 1):S75-S78

49. Hung L, Kumar V: Specific inhibition of gene expression and transactivation functions of hepatitis $B$ virus $X$ protein and c-myc by small interfering RNAs. FEBS Lett 2004, 560:210-214. 
50. Han Q, Zhang C, Zhang J, Tian Z: Reversal of hepatitis B virus-induced immune tolerance by an immunostimulatory $3 p-H B x-s i R N A s$ in a retinoic acid inducible gene I-dependent manner. Hepatology 2011, 54:1179-1189.

51. Reynolds A, Leake D, Boese Q, Scaringe S, Marshall WS: Rational siRNA design for RNA interference. Nat Biotechnol 2004, 22:326-330.

52. Morrissey DV, Blanchard K, Shaw L, Jensen K, Lockridge JA, et al: Activity of stabilized short interfering RNA in a mouse model of hepatitis $B$ virus replication. Hepatology 2005, 41:1349-1356.

53. Morrissey DV, Lockridge JA, Shaw L, Blanchard K, Jensen K, et al: Potent and persistent in vivo anti-HBV activity of chemically modified siRNAs. Nat Biotechnol 2005, 23:1002-1007.

54. Xuan B, Qian Z, Hong J, Huang W: EsiRNAs inhibit hepatitis B virus replication in mice model more efficiently than synthesized siRNAs. Virus Res 2006, 118:150-155.

55. Aigner A: Gene silencing through RNA interference (RNAi) in vivo: strategies based on the direct application of siRNAs. J Biotechnol 2006, 124:12-25.

56. Kim SI, Shin D, Choi TH, Lee JC, Cheon GJ, et al: Systemic and specific delivery of small interfering RNAs to the liver mediated by apolipoprotein A-I. Mol Ther 2007, 15:1145-1152.

57. Garcia T, Li J, Sureau C, Ito K, Qin Y, Wands J, Tong S: Drastic reduction in the production of subviral particles does not impair hepatitis B virus virion secretion. J Virol 2009, 83:11152-11165.

58. Kuhns MC, Kleinman SH, McNamara AL, Rawal B, Glynn S, Busch MP, REDS Study Group: Lack of correlation between HBsAg and HBV DNA levels in blood donors who test positive for $\mathrm{HBsAg}$ and anti-HBc: implications for future HBV screening policy. Transfusion 2004, 44:1332-1339.

59. Tian YJ, Xu Y, Zhang ZH, Meng ZJ, Tan L, et al: A substitution at the amino acid position 122 of hepatitis $B$ surface antigen ( $\mathrm{HBsAg}$ ) strongly impairs the antigenicity of HBsAg. J Clin Microbiol 2007, 45:2971-2978.

60. Mendy ME, Kaye $S$, van der Sande M, Rayco-Solon P, Waight PA, et al: Application of real-time PCR to quantify hepatitis B virus DNA in chronic carriers in The Gambia. Virology 2006, 3:23.

61. Lu M, Yao X, Xu Y, Lorenz H, Dahmen U, et al: Combination of an antiviral drug and immunomodulation against hepadnaviral infection in the woodchuck model. J Virol 2008, 82:2598-2603.

62. Meng Z, Xu Y, Wu J, Tian Y, Kemper T, et al: Inhibition of hepatitis B virus gene expression and replication by endoribonuclease-prepared siRNA. $J$ Virol Methods 2008, 150:27-33.

63. von Freyend MJ, Untergasser A, Arzberger S, Oberwinkler $\mathrm{H}$, Drebber $\mathrm{U}$, et al: Sequential control of hepatitis B virus in a mouse model of acute, selfresolving hepatitis B. J Viral Hepat 2011, 18:216-226.

64. Zhang $X$, Zhang $E$, Ma Z, Pei R, Jiang $M$, et al: Modulation of hepatitis $B$ virus replication and hepatocyte differentiation by MicroRNA-1. Hepatology 2011, 53:1476-1485

doi:10.1186/1743-422X-10-214

Cite this article as: Li et al.: Inhibition of hepatitis B virus (HBV) gene expression and replication by $H B x$ gene silencing in a hydrodynamic injection mouse model with a new clone of HBV genotype B. Virology Journal 2013 10:214.

\section{Submit your next manuscript to BioMed Central and take full advantage of:}

- Convenient online submission

- Thorough peer review

- No space constraints or color figure charges

- Immediate publication on acceptance

- Inclusion in PubMed, CAS, Scopus and Google Scholar

- Research which is freely available for redistribution 